Supporting information

\title{
One-pot production of 2,5-furandimethanol from fructose co-catalyzed with formic acid and heterogeneous Co catalysts
}

Ling $\mathrm{Xu}^{a}$, Renfeng $\mathrm{Nie}^{a, b, *}$, Xilei Lyu ${ }^{a}$, Yuxi Jiang ${ }^{a}$, Xiwen $\mathrm{Wei}^{a}$, Xiuyang $\mathrm{Lu}^{a, *}$

${ }^{a}$ Key Laboratory of Biomass Chemical Engineering of Ministry of Education, College of Chemical and Biological Engineering, Zhejiang University, Hangzhou 310027, P.R. China

${ }^{b}$ College of Chemical Engineering, Zhengzhou University, Zhengzhou 450001, P.R. China

E-mail: luxiuyang@zju.edu.cn; refinenie@163.com

\section{Experimental Procedures}

\section{Materials}

1,10-phenanthroline (99\%) was purchased from Innochem, China. Poly(enthylene glycol)-block-poly(propylene glycol)-block-poly(enthylene glycol) (P123, Mn 5800) was purchased from Sigma-Aldrich. Fructose (99\%), $\mathrm{Co}(\mathrm{OAc})_{2} \cdot 4 \mathrm{H}_{2} \mathrm{O}(99.9 \%)$, $\mathrm{Ni}(\mathrm{OAc})_{2} \cdot 4 \mathrm{H}_{2} \mathrm{O}(99.9 \%), \mathrm{Cu}(\mathrm{OAc})_{2} \cdot \mathrm{H}_{2} \mathrm{O}(99 \%)$ and $\mathrm{Fe}(\mathrm{OAc})_{2}(99 \%)$ were purchased from Aladdin Chemicals. Formic acid (98\%), 5-hydroxymethylfurfural (97\%), 2,5furandimethanol (98\%) and 5-methyl-2-furranmethanol (97\%) were purchased from Macklin, China. Tetraethyl orthosilicate (AR), HCl (36.0-38.0\%), HF ( $\geq 40 \%), 1,4-$ dioxane $(\geq 99.5 \%)$, methanol $(\geq 99.5 \%)$ and ethanol $(\geq 99.5 \%)$ were purchased from Sinopharm Chemical Reagent Co. Ltd, China. All chemicals were used without any further treatment.

\section{Catalyst preparation}

Preparation of SBA-15: Pluronic polymer surfactant P123 was used as structure- 
directing agent. First, $6 \mathrm{~g} \mathrm{P123}$ was dissolved in the $200 \mathrm{~g} 1.6 \mathrm{M} \mathrm{HCl}$ aqueous solution, the resulting solution was stirred at $40^{\circ} \mathrm{C}$ until the solution became clear. Then, $12.75 \mathrm{~g}$ TEOS was added dropwise into this solution under stirring. The mixture was kept under stirring at $40{ }^{\circ} \mathrm{C}$ for $12 \mathrm{~h}$. This mixed solution was then transferred into a Teflon-lined autoclave and heated to and kept at $100{ }^{\circ} \mathrm{C}$ for $24 \mathrm{~h}$. Finally, white precipitates were collected, filtered and washed with water, dried, and calcined at $550{ }^{\circ} \mathrm{C}$ for $6 \mathrm{~h}$ at a heating rate of $4^{\circ} \mathrm{C} / \mathrm{min}$ in a tube furnace to remove the organic template.

Co-NC catalyst was prepared via pyrolysis of the mixture of $\left.\mathrm{Co}(\mathrm{phen})_{2} \mathrm{OAc}\right)_{2}$ and SBA-15 in nitrogen atmosphere. Typically, $\mathrm{Co}(\mathrm{OAc})_{2} \cdot 4 \mathrm{H}_{2} \mathrm{O}(124 \mathrm{mg})$ and $1,10-$ phenanthroline monohydrate $(198 \mathrm{mg})$ were added into $25 \mathrm{~mL}$ ethanol to form a transparent solution. After that, SBA-15 (0.2495 g) was added and the suspension was sonicated for $10 \mathrm{~min}$. The mixture was stirred at $60{ }^{\circ} \mathrm{C}$ overnight. After ethanol was removed by rotary evaporation, the solid was dried, and heated to a $700{ }^{\circ} \mathrm{C}$ in $\mathrm{N}_{2}$ atmosphere at a heating rate of $2{ }^{\circ} \mathrm{C} / \mathrm{min}$ and kept for $2 \mathrm{~h}$. The calcinated solid was treated by $\mathrm{HF}$ and $\mathrm{HCl}$ solution in order to completely remove SBA-15 and soluble cobalt species. The resulting sample was thoroughly washed with DI water until free of $\mathrm{Co}^{2+}$, dried and named as Co-NC. Replacing cobalt acetate with nickel acetate, ferric acetate or copper acetate gave rise to $\mathrm{Ni}-\mathrm{NC}, \mathrm{Fe}-\mathrm{NC}$ or $\mathrm{Cu}-\mathrm{NC}$, respectively.

\section{Characterizations}

Powder X-ray diffraction (XRD) was carried out with Ni-filtered $\mathrm{Cu} K \alpha(\lambda=0.154$ $\mathrm{nm}$ ) operating at $40 \mathrm{kV}$ and $30 \mathrm{~mA}$ on a Bruker D8 diffractometer. $\mathrm{N}_{2}$ adsorption was carried out at $77 \mathrm{~K}$ using an auto-adsorption analyzer (Micromeritics, 3Flex). X-ray photoelectron spectra (XPS) were recorded on a Thermo Scientific ESCALab 250Xi employing a $200 \mathrm{~W}$ monochromatic $\mathrm{Al} \mathrm{K} \alpha$ radiation $(h v=1486.6 \mathrm{eV}) . \mathrm{C} 1 \mathrm{~s}$ at $284.6 \mathrm{eV}$ was used for calibrating the XPS spectra.

\section{Catalytic reactions}

The reactions were carried out in an autoclave $(8 \mathrm{~mL})$ purchased from Zhengxin, China. In a typical run, $30 \mathrm{mg}$ fructose, $20 \mathrm{mg}$ catalyst, a certain amount of FA and 3.5 
$\mathrm{mL}$ solvent were added into the autoclave. The sealed autoclave was purged, pressurized with $\mathrm{N}_{2}$ to $0.5 \mathrm{MPa}$ and heated to the treatment temperature under magnetic stirring $(500 \mathrm{rpm})$. After the completion of reaction, the autoclave was quickly soaked within cold water. The liquid was diluted with methanol. The products and substrate were analyzed by high performance liquid chromatography (HPLC). The catalyst was successively washed by methanol for 3 times and then dried at $60{ }^{\circ} \mathrm{C}$ for $12 \mathrm{~h}$. The recovered catalyst was submitted to the next batch of reaction.

\section{Analysis method}

Fructose, HMF, FDM, FA and other by-products were quantitatively analyzed via high performance liquid chromatography (HPLC, Agilent 1100) with a colum (Aminex HPX-87H, $300 \mathrm{~mm} \times 7.8 \mathrm{~mm}$ I.D., Bio-Rad Laboratories, Inc.). The flow rate of mobile phase $\left(5 \mathrm{mmol} / \mathrm{L} \mathrm{H}_{2} \mathrm{SO}_{4}\right)$ was $0.4 \mathrm{~mL} / \mathrm{min}$. The temperature of the column and the RID were $60{ }^{\circ} \mathrm{C}$ and $35{ }^{\circ} \mathrm{C}$, respectively. Reactant mole conversions were obtained as the number of moles of reactant consumed divided by the initial number of moles of reactant added to the reactor. Selectivity was calculated by the number of moles of product recovered divided by the number of moles of reactant reacted. A quantitative analysis was performed using calibration curves for every compound in the mixture. All data were calculated by the average of three replicate experiments. 
Table S1 Representative works for FDM production from fructose.

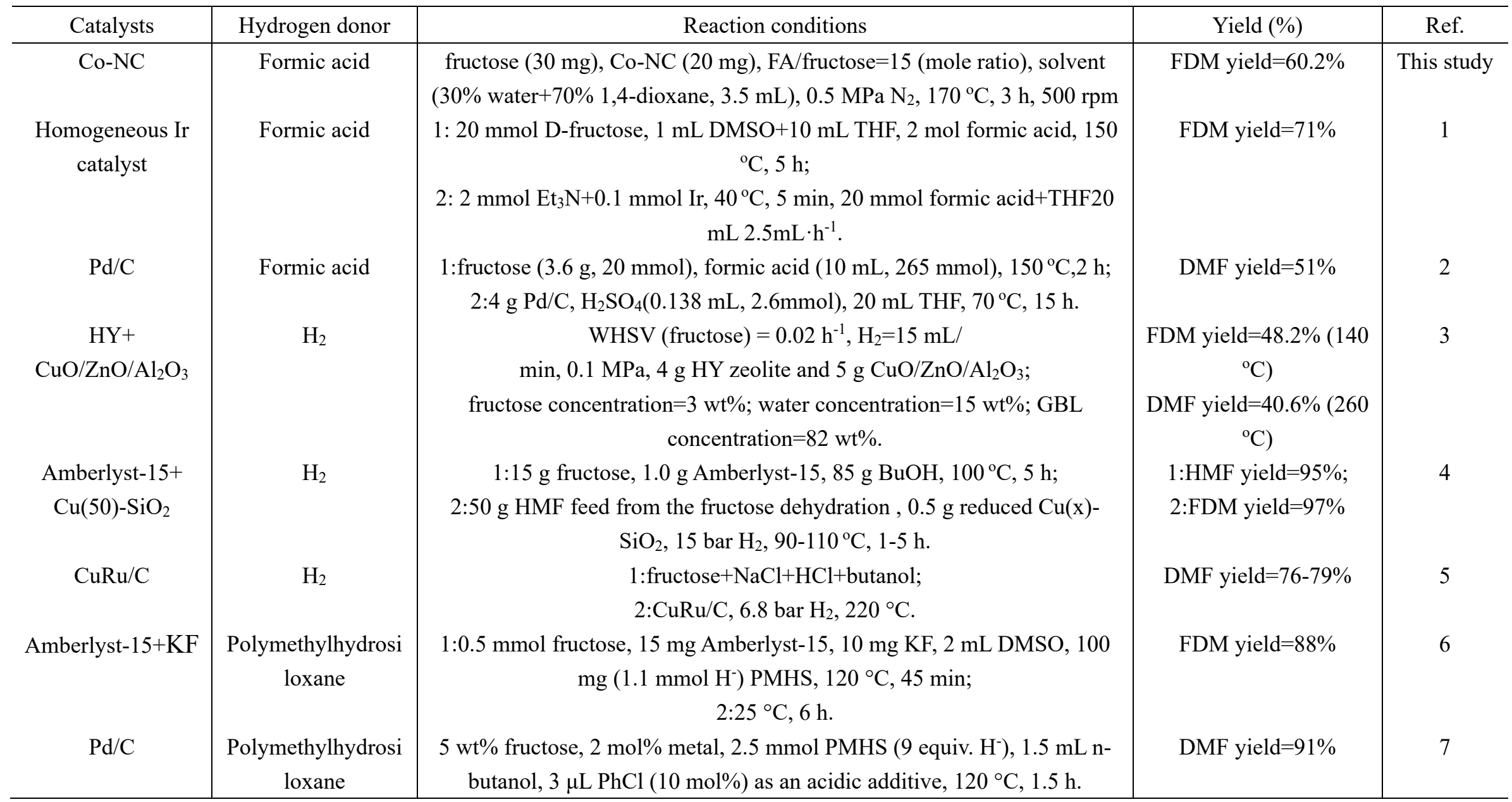



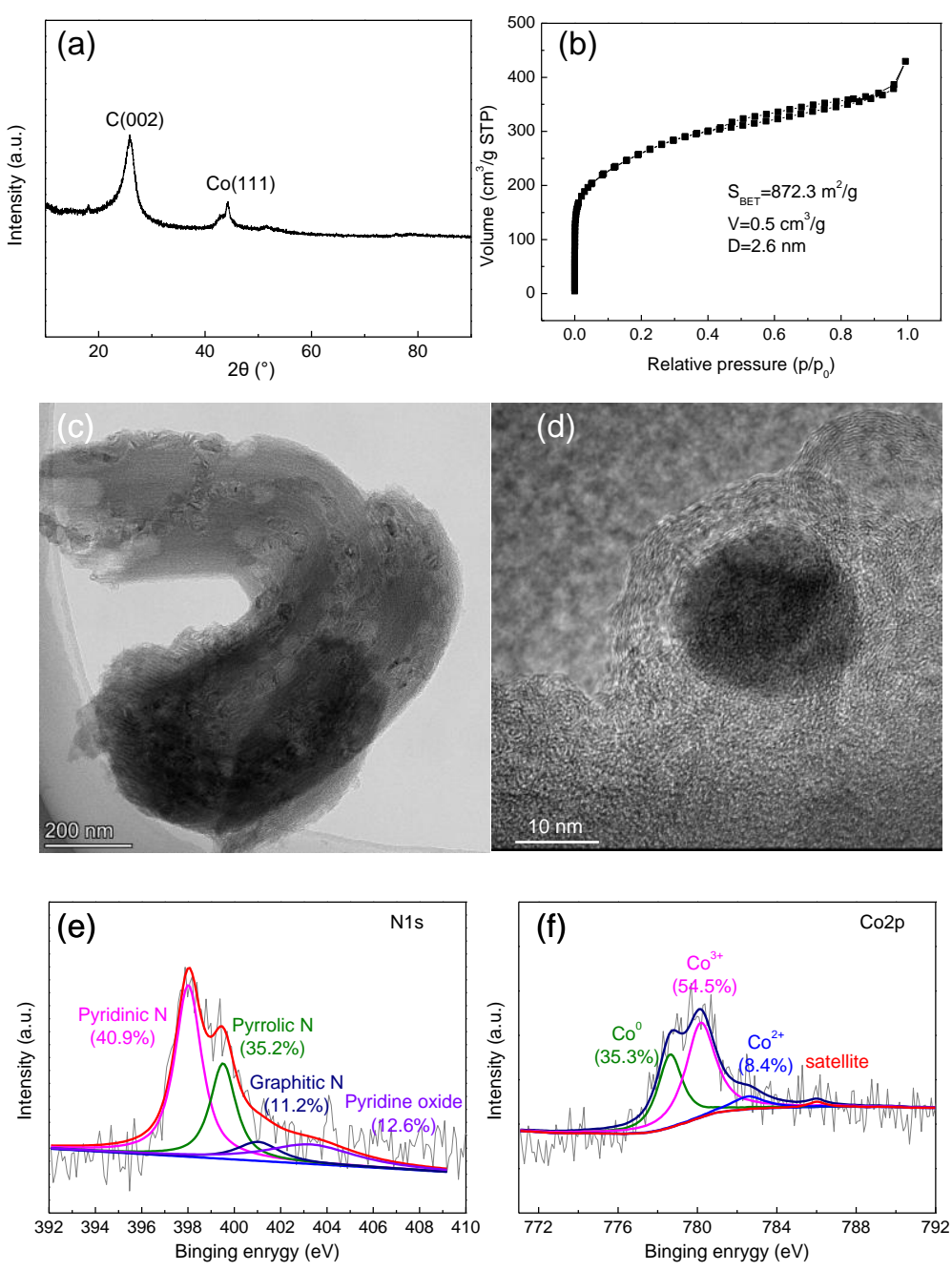

Fig. S1 (a) XRD pattern, (b) $\mathrm{N}_{2}$ adsorption/desorption isotherm, (c and d) TEM images, (e) N1s and (f) Co2p spectra of Co-NC.

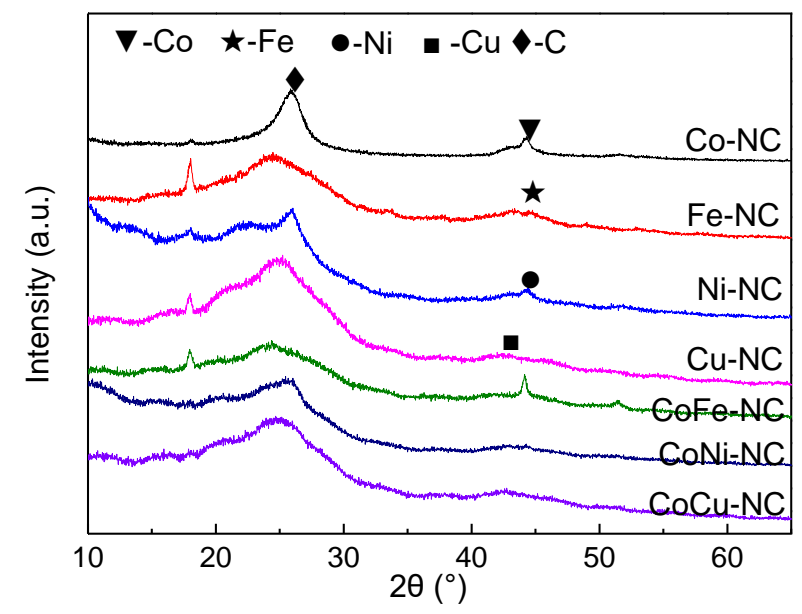

Fig. S2 XRD patterns of of different Me-NC catalysts. 


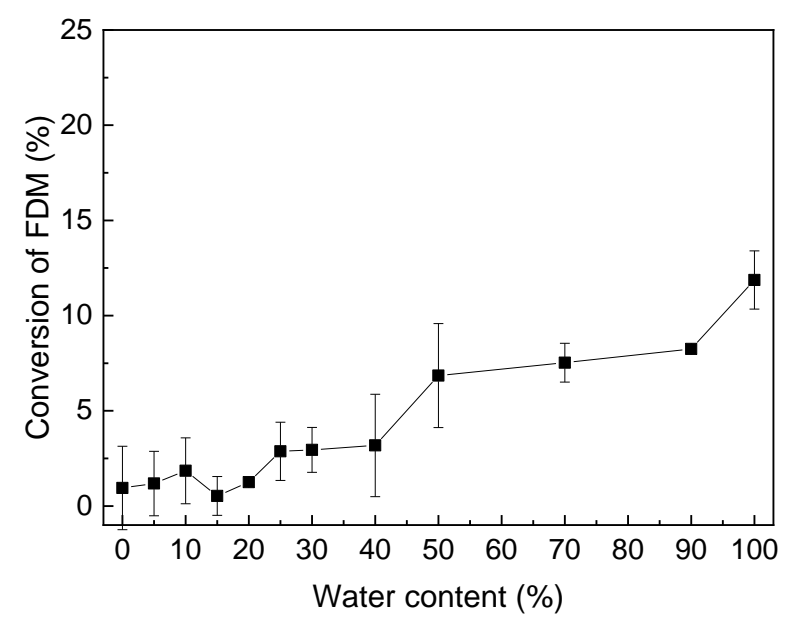

Fig. S3 Effect of water content on the stability of FDM.

Reaction conditions: FDM (30 mg), solvent (water+1,4-dioxane, $3.5 \mathrm{~mL}$ ), $0.5 \mathrm{MPa} \mathrm{N}$, $160^{\circ} \mathrm{C}, 4 \mathrm{~h}, 500 \mathrm{rpm}$.

Table S2 Effect of fructose concentration on one-pot transformation of fructose over Co-NC.

\begin{tabular}{|c|c|c|c|c|}
\hline Entry & $\begin{array}{c}\text { Concentration } \\
/ \text { wt. } \%\end{array}$ & Reaction conditions & $\begin{array}{c}\text { Conv./ } \\
\%\end{array}$ & $\begin{array}{c}\text { Yield/ } \\
\% \\
\end{array}$ \\
\hline 1 & 0.86 & $\begin{array}{c}\text { fructose }(30 \mathrm{mg}), \text { Co-NC }(20 \mathrm{mg}), \\
\text { FA/fructose }=15 \text { (mole ratio), solvent } \\
\text { (water+1,4-dioxane, } 3.5 \mathrm{~mL}), 160^{\circ} \mathrm{C}, 4 \mathrm{~h} \\
\text { fructose }(90 \mathrm{mg}), \mathrm{Co}-\mathrm{NC}(60 \mathrm{mg}),\end{array}$ & 100 & 58.6 \\
\hline 2 & 2.57 & $\begin{array}{c}\mathrm{FA} / \text { fructose }=15 \text { (mole ratio), solvent } \\
\text { (water+1,4-dioxane, } 3.5 \mathrm{~mL}), 160^{\circ} \mathrm{C}, 4 \mathrm{~h} \\
\text { fructose }(180 \mathrm{mg}), \mathrm{Co}-\mathrm{NC}(120 \mathrm{mg})\end{array}$ & 98.2 & 55.3 \\
\hline 3 & 5.14 & $\begin{array}{c}\mathrm{FA} / \text { fructose }=15 \text { (mole ratio), solvent } \\
\text { (water+1,4-dioxane, } 3.5 \mathrm{~mL}), 160^{\circ} \mathrm{C}, 4 \mathrm{~h} \\
\text { fructose }(180 \mathrm{mg}), \mathrm{Co}-\mathrm{NC}(120 \mathrm{mg}),\end{array}$ & 91.5 & 50.7 \\
\hline 4 & 5.14 & $\begin{array}{c}\mathrm{FA} / \text { fructose }=15 \text { (mole ratio), solvent } \\
\text { (water+1,4-dioxane, } 3.5 \mathrm{~mL}), 160^{\circ} \mathrm{C}, 6 \mathrm{~h}\end{array}$ & 100 & 56.9 \\
\hline
\end{tabular}


Table S3 Reaction rate constants $(k)$ of transformation of fructose and HMF at different temperature.

\begin{tabular}{|c|c|c|c|c|c|c|}
\hline \multirow[t]{2}{*}{$\mathrm{T} / \mathrm{K}$} & \multicolumn{2}{|c|}{$\begin{array}{l}\text { Dehydration of } \\
\text { fructose }\end{array}$} & \multicolumn{2}{|c|}{ CTH of HMF } & \multicolumn{2}{|c|}{$\begin{array}{l}\text { One-pot dehydration- } \\
\text { hydrogenation of } \\
\text { fructose }\end{array}$} \\
\hline & $k / \mathrm{h}^{-1}$ & $\mathrm{R}^{2}$ & $k / \mathrm{h}^{-1}$ & $\mathrm{R}^{2}$ & $k / \mathrm{h}^{-1}$ & $\mathrm{R}^{2}$ \\
\hline 413 & 0.3610 & 0.9826 & 0.5446 & 0.9636 & 0.5156 & 0.9927 \\
\hline 423 & 0.6793 & 0.9966 & 0.5974 & 0.9507 & 0.7722 & 0.9904 \\
\hline 433 & 0.9069 & 0.9815 & 0.7696 & 0.9504 & 1.2153 & 0.9959 \\
\hline 443 & 1.3274 & 0.9512 & 0.9166 & 0.9706 & 2.6965 & 0.9515 \\
\hline
\end{tabular}
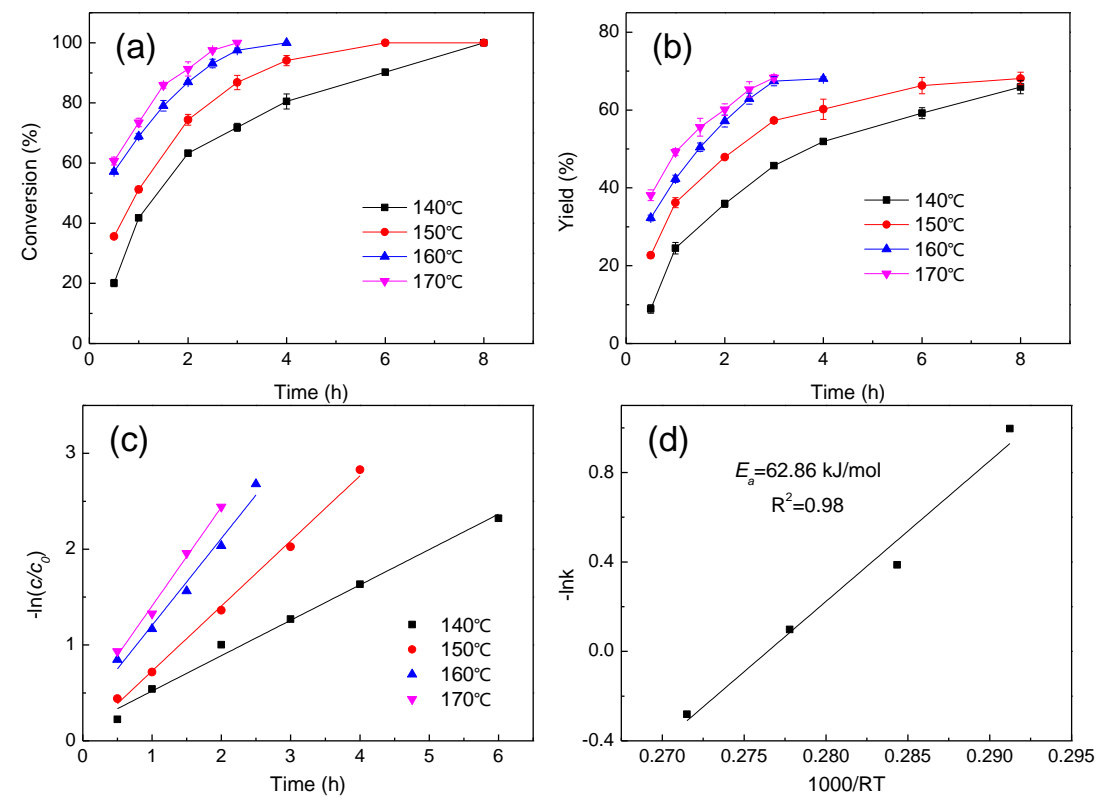

Fig. S4 (a, b) Dehydration of fructose at different temperatures. (c) Pseudo-first-order plot of $\ln \left(c / c_{0}\right)$ against reaction time for dehydration of fructose. (d) Plot of $\ln k$ against $1 / T$ for dehydration of fructose. Reaction conditions: fructose $(30 \mathrm{mg}), \mathrm{FA} /$ fructose $=15$ (mole ratio), solvent ( $30 \%$ water $+70 \%$ 1,4-dioxane, $3.5 \mathrm{~mL}), 0.5 \mathrm{MPa} \mathrm{N}_{2}, 160{ }^{\circ} \mathrm{C}, 4 \mathrm{~h}$, $500 \mathrm{rpm}$. 

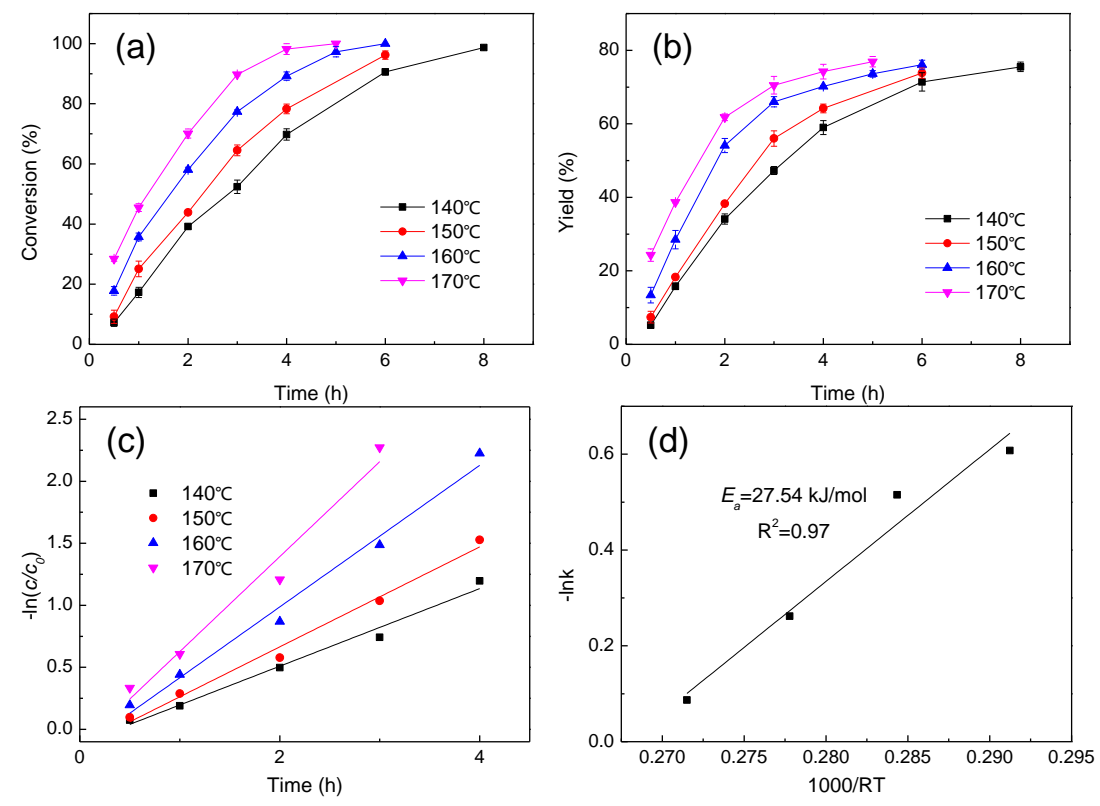

Fig. S5 (a, b) Catalytic transfer hydrogenation of HMF at different temperatures. (c) Pseudo-first-order plot of $\ln \left(c / c_{0}\right)$ against reaction time for catalytic transfer hydrogenation of HMF. (d) Plot of $\ln k$ against $1 / T$ for catalytic transfer hydrogenation of HMF. Reaction conditions: HMF (30 mg), FA/HMF=15 (mole ratio), Co-NC (20 $\mathrm{mg})$, solvent ( $30 \%$ water $+70 \%$ 1,4-dioxane, $3.5 \mathrm{~mL}), 0.5 \mathrm{MPa} \mathrm{N} 2,160^{\circ} \mathrm{C}, 4 \mathrm{~h}, 500 \mathrm{rpm}$.

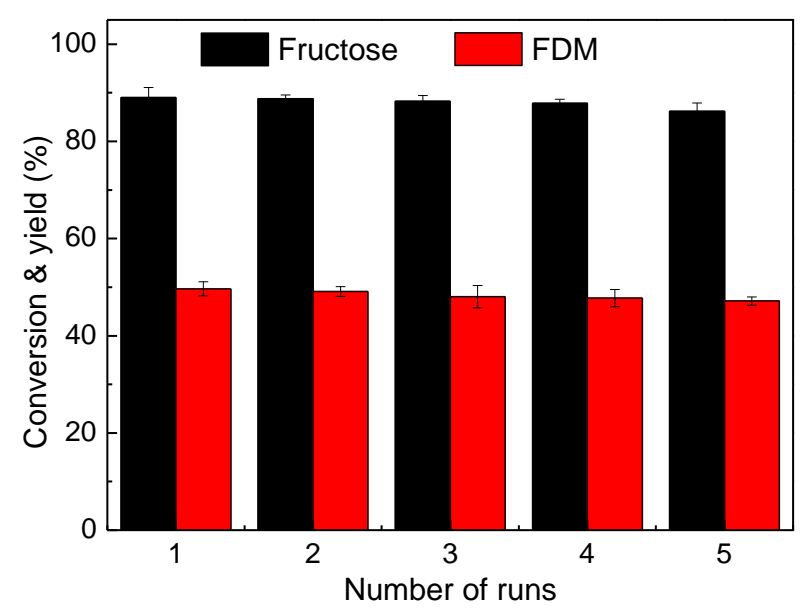

Fig. S6 Recycling test of Co-NC for one-pot dehydration-hydrogenation of fructose. Reaction conditions: fructose $(30 \mathrm{mg}), \mathrm{FA} /$ fructose $=15$ (mole ratio), Co-NC (20 mg), solvent (30\% water+70\% 1,4-dioxane, $3.5 \mathrm{~mL}), 0.5 \mathrm{MPa} \mathrm{N}_{2}, 170^{\circ} \mathrm{C}, 1 \mathrm{~h}, 500 \mathrm{rpm}$. 


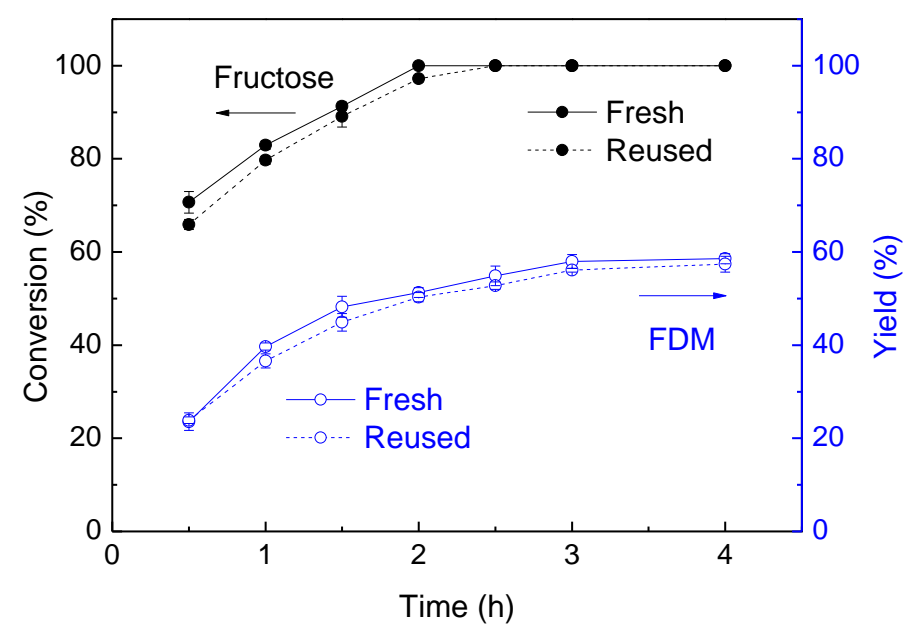

Fig. S7 Time course of one-pot transformation of fructose over fresh and reused CoNC. Reaction conditions: fructose $(30 \mathrm{mg}), \mathrm{FA} / \mathrm{substrate}=15$ (mole ratio), Co-NC (20 $\mathrm{mg}$ ), solvent (30\% water+70\% 1,4-dioxane, $3.5 \mathrm{~mL}$ ), $0.5 \mathrm{MPa} \mathrm{N} 2,160{ }^{\circ} \mathrm{C}, 500 \mathrm{rpm}$.
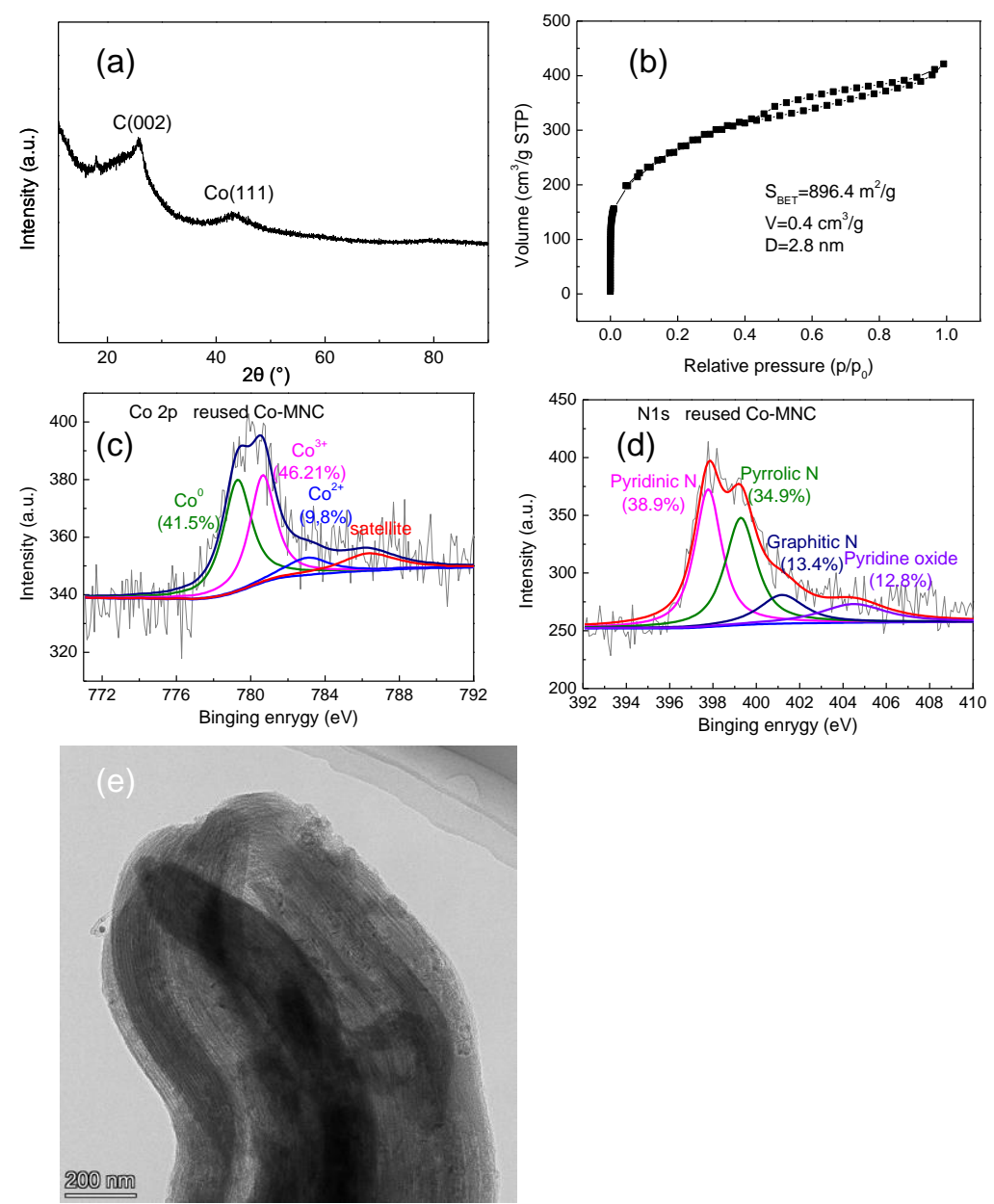

Fig. S8 (a) XRD patterns, (b) $\mathrm{N}_{2}$ adsorption/desorption isotherms, (c) N1s spectra, (d) Co2p spectra (e) TEM images of reused Co-NC. 


\section{References}

(1) Thananatthanachon, T.; Rauchfuss, T. B. Efficient route to hydroxymethylfurans from sugars via transfer hydrogenation. ChemSusChem 2010, 3, 1139-1141.

(2) Thananatthanachon, T.; Rauchfuss, T. B. Efficient production of the liquid fuel 2,5dimethylfuran from fructose using formic acid as a reagent. Angew. Chem. -Int. Edit. 2010, 49, 6616-6618.

(3) Xiang, X.; Cui, J.; Ding, G.; Zheng, H.; Zhu, Y.; Li, Y. One-step continuous conversion of fructose to 2,5-dihydroxymethylfuran and 2,5-dimethylfuran. ACS Sustain. Chem. Eng. 2016, 4, 4506-4510.

(4) Upare, P. P.; Hwang, Y. K.; Hwang, D. W. An integrated process for the production of 2,5-dihydroxymethylfuran and its polymer from fructose. Green Chem. 2018, 20, 879-885.

(5) Román-Leshkov, Y.; Barrett, C. J.; Liu, Z. Y.; Dumesic, J. A. Production of dimethylfuran for liquid fuels from biomass-derived carbohydrates. Nature 2007, 447, 982-985.

(6) Zhao, W.; Wu, W.; Li, H.; Fang, C.; Yang, T.; Wang, Z.; He, C.; Yang, S. Quantitative synthesis of 2,5-bis(hydroxymethyl)furan from biomass-derived 5hydroxymethylfurfural and sugars over reusable solid catalysts at low temperatures. Fuel 2018, 217, 365-369.

(7) Li, H.; Zhao, W.; Riisager, A.; Saravanamurugan, S.; Wang, Z.; Fang, Z.; Yang, S. A Pd-catalyzed in situ domino process for mild and quantitative production of 2,5dimethylfuran directly from carbohydrates. Green Chem. 2017, 19, 2101-2106. 